\title{
The metabolic syndrome of fructose-fed rats: Effects of long-chain polyunsaturated $\omega 3$ and $\omega 6$ fatty acids. I. Intraperitoneal glucose tolerance test
}

\author{
ZOHEIR MELLOUK ${ }^{1}$, TAREK HACHIMI IDRISSI ${ }^{2}$, KARIM LOUCHAMI $^{2}$, EMELINE HUPKENS $^{2}$, \\ WILLY J. MALAISSE ${ }^{2}$, DALILA AIT YAHIA ${ }^{1}$ and ABDULLAH SENER ${ }^{2}$ \\ ${ }^{1}$ Department of Biology, Es-Sénia University, Oran, Algeria; ${ }^{2}$ Laboratory of Experimental \\ Hormonology, Université Libre de Bruxelles, Brussels, Belgium
}

Received June 29, 2011; Accepted August 12, 2011

DOI: 10.3892/ijmm.2011.781

\begin{abstract}
The present series of experiments aim mainly at investigating the possible influence of changes in the composition of dietary lipids (sunflower oil, salmon oil, safflower oil) upon the metabolic syndrome found in rats exposed to a fructose-rich diet. For purpose of comparison, a control group of rats received the sunflower oil diet with substitution of fructose by starch. An intraperitoneal glucose tolerance test, performed after overnight starvation fifty days after the start of the experiments at the 6th week after birth, indicated, as expected, impaired tolerance to glucose and deterioration of insulin sensitivity (HOMA index), without changes in the insulinogenic index, when comparing the fructose-fed rats to the starch-fed rats both exposed to the sunflower oil diet. In the fructose-fed rats, enrichment of the diet by long-chain polyunsaturated $\omega 3$ fatty acids supplied by salmon oil, a modest improvement of insulin sensitivity was opposed, in term of glucose homeostasis, by a decreased secretory response to glucose of insulin-producing cells. Last, in the fructose-fed rats, the partial substitution of sunflower oil by safflower oil rich in long-chain polyunsaturated $\omega 6$ fatty acids further deteriorated glucose homeostasis, with a higher mean HOMA index and a severe decrease of the insulinogenic index. These findings justify further investigations on such items as the time course for changes in metabolic and hormonal variables and both the metabolic and secretory responses of isolated pancreatic islets to selected nutrient secretagogues.
\end{abstract}

\section{Introduction}

A metabolic syndrome with insulin resistance, hyperinsulinemia and hypertension is known to prevail in rats

Correspondence to: Professor Willy J. Malaisse, Laboratory of Experimental Hormonology, Université Libre de Bruxelles, 808 Route de Lennik, B-1070 Brussels, Belgium

E-mail: malaisse@ulb.ac.be

Key words: metabolic syndrome, fructose-fed rats, long-chain polyunsaturated $\omega 3$ and $\omega 6$ fatty acids, intraperitoneal glucose tolerance test exposed to a high dietary supply of D-fructose (1). Attention was recently drawn to both the comparison between rats exposed to either a fructose-enriched diet or fructose-enriched drinking water, as well as the reversibility of the fructose-induced metabolic perturbations (2).

Rats deprived of a dietary supply of long-chain polyunsaturated $\omega 3$ fatty acids also develop a metabolic syndrome with liver steatosis, visceral obesity, insulin resistance, hypertension and resulting cardiac hypertrophy (3-8).

The present experiments aim mainly at exploring the effects of long-chain polyunsaturated $\omega 3$ and $\omega 6$ fatty acids in rats exposed from the 8th week after birth and for the ensuing 8 weeks to a fructose-enriched diet. More precisely, a first comparison deals with rats fed a sunflower oil diet and given access to either a control diet or a fructose-enriched diet obtained by substitution of starch by D-fructose. In this first comparison, the two diets contained 5.0\% (w/w) sunflower oil, containing $<0.1 \%$ of its total fatty acid content as long-chain polyunsaturated $\omega 3$ fatty acids. In the second set of comparisons, the just-mentioned rats exposed to the fructose-rich and sunflower oil-containing diet served as the control fructose-fed rats. In another group of rats, part of the sunflower oil $(1.6 \%, \mathrm{w} / \mathrm{w})$ in the fructose-rich diet was replaced by an equal amount of salmon oil rich in $\omega 3$ fatty acids. Last, in the third group of rats considered in this second set of comparisons, the same part of the sunflower oil diet $(1.6 \%, \mathrm{w} / \mathrm{w})$ in the fructose-rich diet was substituted by an equal amount of safflower oil diet containing mainly C18:2 $\omega 6$.

This report concerns the results obtained in intraperitoneal glucose tolerance tests (IPGTT) conducted in the rats 50 days after the onset of the present experiments.

\section{Materials and methods}

Four groups of six female Wistar rats each were exposed from the 8th week after birth and for the ensuing 8 weeks to one of the diets defined in Table I. The control rats (Ssun) received $\operatorname{diet} \mathrm{A}$, which represented a diet deprived of both fructose and long-chain polyunsaturated $\omega 3$ fatty acids. The so-called control fructose-fed rats (Fsun) received diet B, which differed from diet A by the substitution of starch by D-fructose. The 
Table I. Composition of the diet $(\mathrm{g} / \mathrm{kg})$.

\begin{tabular}{lcccc}
\hline $\begin{array}{l}\text { Diet } \\
\text { Rats }\end{array}$ & $\begin{array}{c}\text { A } \\
\text { Ssun }\end{array}$ & $\begin{array}{c}\text { B } \\
\text { Fsun }\end{array}$ & $\begin{array}{c}\text { C } \\
\text { Fsal }\end{array}$ & $\begin{array}{c}\text { D } \\
\text { Fsaf }\end{array}$ \\
\hline Casein & 200 & 200 & 200 & 200 \\
Fructose & - & 640 & 640 & 640 \\
Cellulose & 50 & 50 & 50 & 50 \\
Starch & 640 & - & - & - \\
Sunflower oil & 50 & 50 & 34 & 34 \\
Salmon oil & - & - & 16 & - \\
Safflower oil & - & - & - & 16 \\
Vitamins & 20 & 20 & 20 & 20 \\
Mineral salts & 40 & 40 & 40 & 40 \\
\hline
\end{tabular}

comparison between (Ssun) and (Fsun) rats thus informed on the effect(s) of the latter substitution in sunflower oil-fed rats. The diet $\mathrm{C}$ offered to the Fsal rats differed from diet $\mathrm{B}$ by the substitution of part of the sunflower oil $(16 \mathrm{~g} / \mathrm{kg})$ by an equal amount $(16 \mathrm{~g} / \mathrm{kg})$ of a long-chain polyunsaturated $\omega 3$ fatty acid-rich salmon oil containing (w/w) 33\% C20:5 $\omega 3$ and 22\% C22:6 $\omega 3$ and, hence by a decrease in the $\mathrm{C} 18: 2 \omega 6$ relative weight content of diet lipids from about 65.0 to $44.3 \%$. The comparison between the (Fsun) and (Fsal) rats was thus relevant to the effects of $\omega 3$ repletion in fructose-fed rats.

Last, the diet $\mathrm{D}$ offered to the Fsaf rats only differed from diet $B$ by the substitution of part of the sunflower oil $(16 \mathrm{~g} / \mathrm{kg})$ by an equal amount $(16 \mathrm{~g} / \mathrm{kg})$ of safflower oil, containing about $9 \%$ saturated fatty acids, $13 \%$ monodesaturated fatty acids (mainly C18:1 109 ) and $77 \%$ long-chain polyunsaturated fatty acids (mainly $\mathrm{C} 18: 2 \omega 6$ ). The estimated $\mathrm{C} 18: 2 \omega 6$ relative weight content of diets B and D amounted, respectively, to 65.0 and $68.9 \%$. Diet D was used for comparison with diet $\mathrm{C}$, which both contained the same amount of sunflower oil diet but vastly different amounts of $\omega 3$ fatty acids and, hence, different $\omega 3 / \omega 6$ ratio. Incidentally, the safflower oil contained equal amounts of the cis-9, trans 11 and trans10, cis12 active isomers of $\mathrm{C} 18: 2 \omega 6$.

Fifty days after the start of the present experiments, all animals underwent, after overnight starvation, an intraperitoneal glucose tolerance test (IPGTT). For such a purpose, $1.0 \mathrm{~g} \mathrm{D}$-glucose $/ \mathrm{kg}$ body weight was administered intraperitoneally as a $50 \%(\mathrm{w} / \mathrm{w})$ D-glucose solution. Blood samples were collected before (time zero) and 15, 30, 60, 90 and $120 \mathrm{~min}$ after the administration of D-glucose.

The plasma concentrations of D-glucose (9) and insulin (10) were measured by methods described in the cited references. These measurements allowed to compute the total and incremental area under the plasma D-glucose and insulin curves (AUC) during the IPGTT, the time zero insulinogenic index, i.e. the ratio between plasma insulin concentrations and the difference between plasma D-glucose concentration and $4.0 \mathrm{mM}$ (taken as the threshold value for stimulation of insulin secretion by the hexose), and the time zero HOMA index for insulin resistance, i.e. the product of plasma D-glucose concentration times plasma insulin concentration.

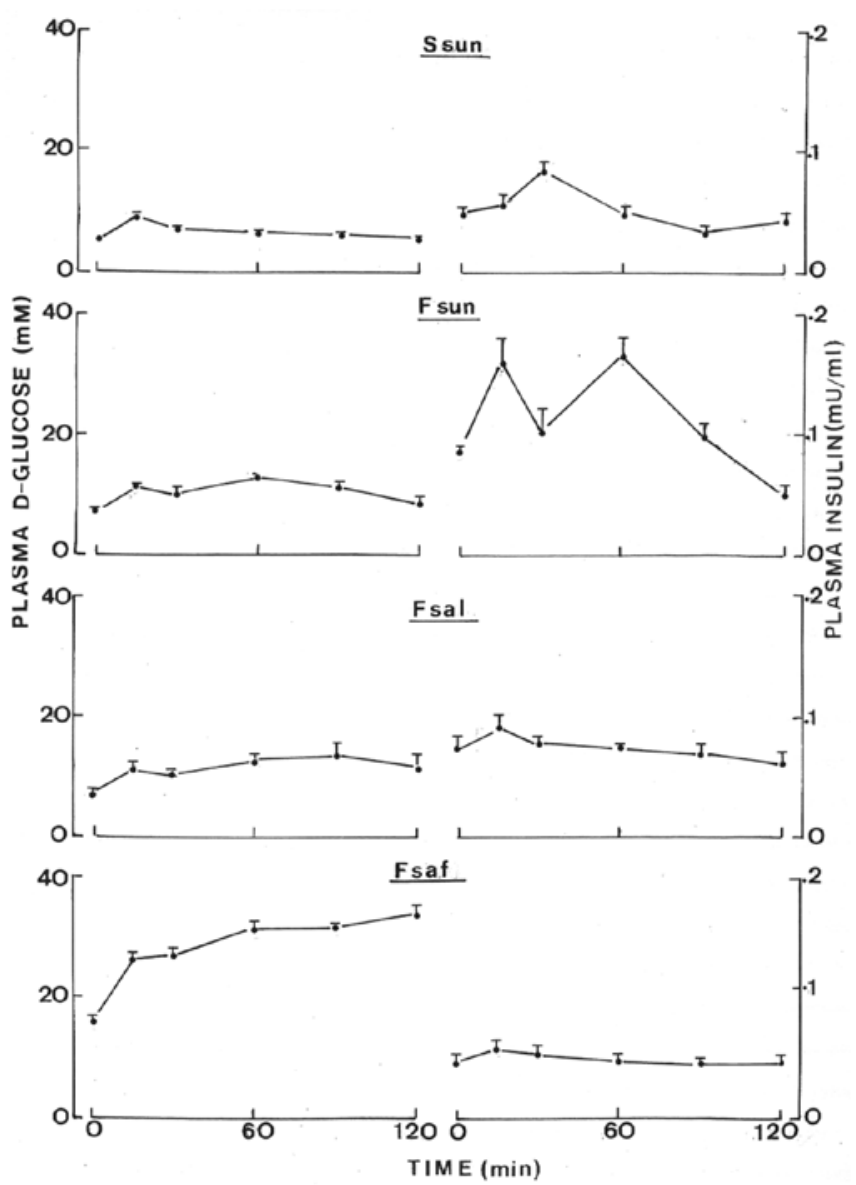

Figure 1. Plasma D-glucose and insulin profile during IPGTT. Mean values $( \pm$ SEM) refer to 5-6 individual observations.

All results are presented as mean values $( \pm$ SEM) together with the number of individual determinations ( $\mathrm{n}$ ). The difference between mean values was assessed by use of Student's t-test.

\section{Results}

Time zero measurements. The profiles for plasma D-glucose and insulin concentrations during the IPGTT in the four groups of rats are illustrated in Fig. 1.

The basal values (time zero of the IPGTT) for plasma D-glucose and insulin concentrations, as well as for the insulinogenic and HOMA indices, are listed in Table I. The plasma D-glucose concentration was lower $(\mathrm{p}<0.025)$ in the (Ssun) rats than in the (Fsun) rats and (Fsal) rats, but much higher $(\mathrm{p}<0.001)$ in the (Fsaf) rats.

The plasma insulin concentration was also lower $(\mathrm{p}<0.003)$ in the (Ssun) rats than in the (Fsun) rats, and comparable $(p>0.38)$ in the latter animals and (Fsal) rats. In the (Fsaf) rats, however, it was lower $(p<0.004)$ than in the other fructose-fed animals and quite close $(\mathrm{p}>0.81)$ to the plasma insulin concentration found in the (Ssun) rats.

As illustrated in Fig. 2, the relationship between basal plasma insulin and plasma D-glucose concentration was vastly different in the (Fsaf) rats than in the other animals. Covariance analysis indicated that the slope of the regression line was significantly lower $(\mathrm{F}=6.282 ; \mathrm{f}=1,19 ; \mathrm{p}<0.025)$ in the former rats (4.30) than in the latter animals (12.60). In other 
Table II. Basal values (time zero of IPGTT).

\begin{tabular}{lcccc}
\hline Rats & $\begin{array}{c}\text { Plasma D-glucose } \\
(\mathrm{mM})\end{array}$ & $\begin{array}{c}\text { Plasma insulin } \\
(\mu \mathrm{U} / \mathrm{ml})\end{array}$ & $\begin{array}{c}\text { Insulinogenic index } \\
(\mathrm{U} / \mathrm{mol})\end{array}$ & $\begin{array}{c}\text { HOMA } \\
(\mathrm{mU} . \mathrm{mM} / \mathrm{l})\end{array}$ \\
\hline Ssun & $5.24 \pm 0.29(6)$ & $49 \pm 6(6)$ & $46.6 \pm 8.1(6)$ & $240 \pm 36(6)$ \\
Fsun & $6.90 \pm 0.62(6)$ & $84 \pm 6(6)$ & $33.9 \pm 5.0(6)$ & $564 \pm 85(6)$ \\
Fsal & $6.88 \pm 0.84(5)$ & $73 \pm 11(5)$ & $33.8 \pm 8.7(5)$ & $468 \pm 122(5)$ \\
Fsaf & $16.12 \pm 0.86(6)$ & $47 \pm 6(6)$ & $4.1 \pm 0.2(6)$ & $770 \pm 162(6)$ \\
\hline
\end{tabular}

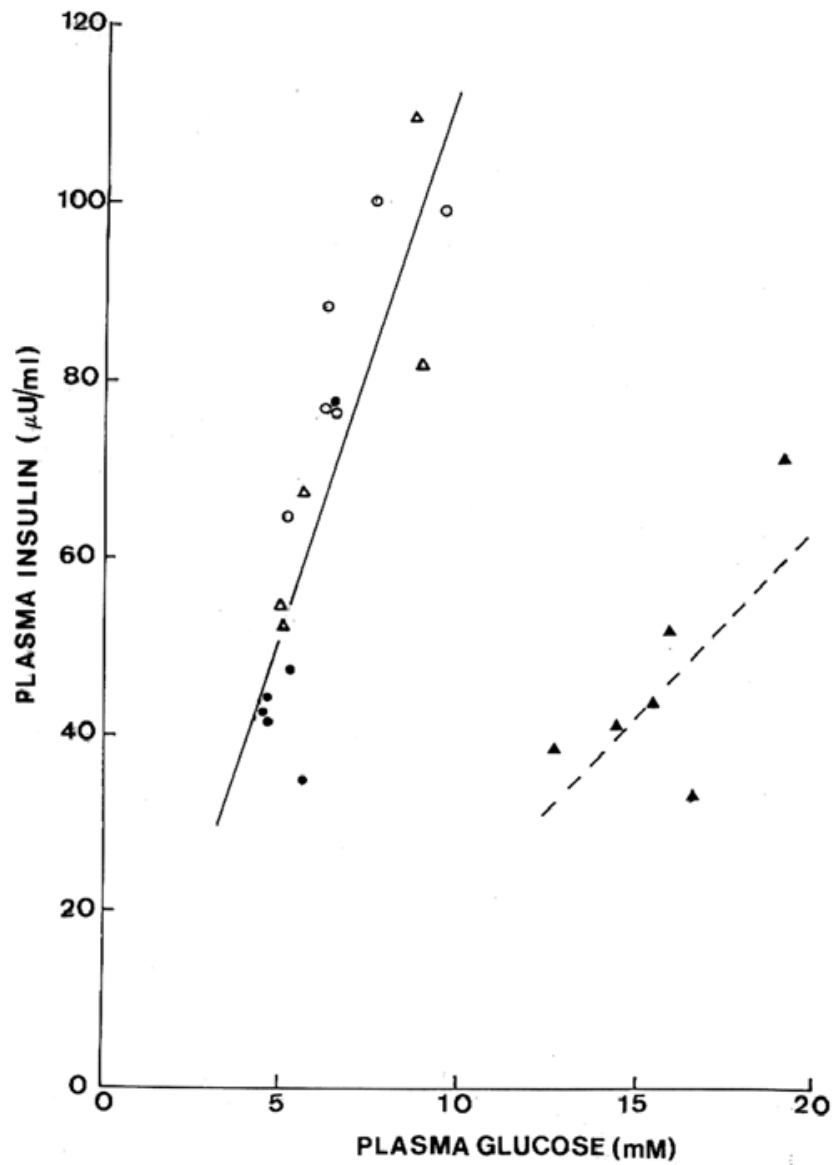

Figure 2. Relationship between plasma insulin and D-glucose concentration at time zero of the IPGTT in (Ssun) rats (closed circles), (Fsun) rats (open circles), (Fsal) rats (open triangles) and (Fsaf) rats (closed triangles). The oblique lines correspond to the regression lines.

words, the insulinogenic index was much lower $(\mathrm{p}<0.001)$ in the (Fsaf) rats $(4.1 \pm 0.2 \mathrm{U} / \mathrm{mol} ; \mathrm{n}=6)$ than in the other animals $(38.3 \pm 4.1 \mathrm{U} / \mathrm{mol} ; \mathrm{n}=17)$.

The HOMA index was lower $(\mathrm{p}<0.001)$ in the (Ssun) rats $(240 \pm 36 \mathrm{mU} \cdot \mathrm{mM} / \mathrm{l} ; \mathrm{n}=6)$ than in the fructose-fed animals (596 $\pm 66 \mathrm{mU} . \mathrm{mM} / \mathrm{l} ; \mathrm{n}=17)$. In the latter animals, such a HOMA index was negatively related to the $\omega 3 / \omega 6$ ratio of the diet (Fig. 3).

Plasma D-glucose concentration during the IPGTT. The peak value for plasma D-glucose concentration was reached earlier ( $\mathrm{p}<0.06$ or less) in the (Ssun) rats $(\min 25.0 \pm 7.4 ; \mathrm{n}=6)$ than in the (Fsun) rats (min 62.5 $\pm 15.7 ; \mathrm{n}=6)$, (Fsal) rats (min 69.0 $\pm 17.5 ; \mathrm{n}=5$ )

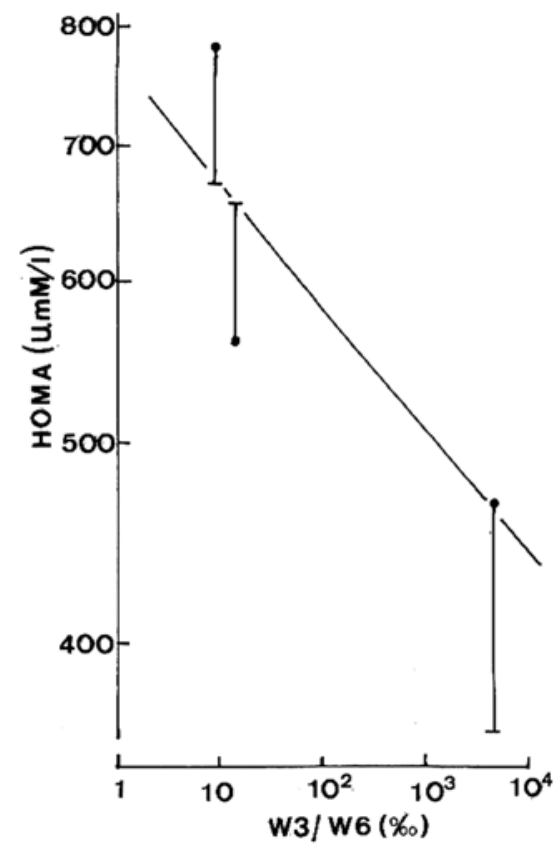

Figure 3. Relationship between the mean HOMA and dietary $\omega 3 / \omega 6$ ratio (logarithmic scales) in fructose-fed rats. Mean values for HOMA $( \pm$ SEM) refer to 5-6 individual observations.

or (Fsaf) rats (min $95.0 \pm 12.0 ; n=6)$. In relative terms, it failed to differ significantly in the four groups of rats, with an overall geometric mean value of $196.1 \pm 9.8 \%(n=23)$ of paired time zero value. In absolute terms, however, it increased $(\mathrm{p}<0.08)$ from $4.11 \pm 0.54 \mathrm{mM}(\mathrm{n}=6)$ in the (Ssun) rats to $6.95 \pm 1.05 \mathrm{mM}(\mathrm{n}=11)$ in the (Fsun) and (Fsal) rats, with a further increase $(\mathrm{p}<0.001)$ to $18.17 \pm 1.81 \mathrm{mM}(\mathrm{n}=6)$ in the (Fsaf) rats (Table II). Both the total and incremental AUC for plasma D-glucose concentration followed a comparable hierarchy as that just mentioned for the peak values of such concentrations. In all respects, the best glucose tolerance was thus recorded in the (Ssun) rats and the worst one in the (Fsaf) rats, with in-between values in the (Fsun) and (Fsal) rats.

Plasma insulin concentration during the IPGTT. The peak increment for plasma insulin concentration was reached at min $18.0 \pm 3.0(n=5)$ and 17.5 $\pm 2.5(n=6)$ in the (Fsal) and (Fsaf) rats, respectively, as compared to min 30.0 $\pm 6.7(n=6)$ and 40.0 $\pm 9.2(\mathrm{n}=6)$ in the (Ssun) and (Fsun) rats, respectively (Table III). It thus occurred earlier $(\mathrm{p}<0.02)$ in the former rats (min $17.7 \pm 1.8 ; n=11)$ than in the latter ones $(\min 35.0 \pm 5.6$; 
Table III. Plasma D-glucose concentration during IPGTT.

\begin{tabular}{|c|c|c|c|c|c|}
\hline \multirow[t]{2}{*}{ Rats } & \multicolumn{2}{|c|}{ Peak increment ${ }^{\mathrm{a}}$} & \multicolumn{2}{|c|}{ AUC (mM.min) } & \multirow[b]{2}{*}{ (n) } \\
\hline & Time (min) & $\Delta(\mathrm{mM})$ & Total & Incremental $^{\mathrm{a}}$ & \\
\hline Ssun & $25.0 \pm 7.4$ & $4.11 \pm 0.54$ & $770 \pm 48$ & $141 \pm 47$ & (6) \\
\hline Fsun & $62.5 \pm 15.7$ & $6.72 \pm 0.92$ & $1,288 \pm 57$ & $460 \pm 105$ & (6) \\
\hline Fsal & $69.0 \pm 17.5$ & $7.22 \pm 2.18$ & $1,384 \pm 156$ & $590 \pm 135$ & (5) \\
\hline Fsaf & $95.0 \pm 12.0$ & $18.17 \pm 1.81$ & $3,513 \pm 94$ & $1,579 \pm 106$ & (6) \\
\hline
\end{tabular}

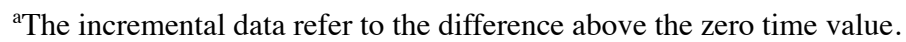

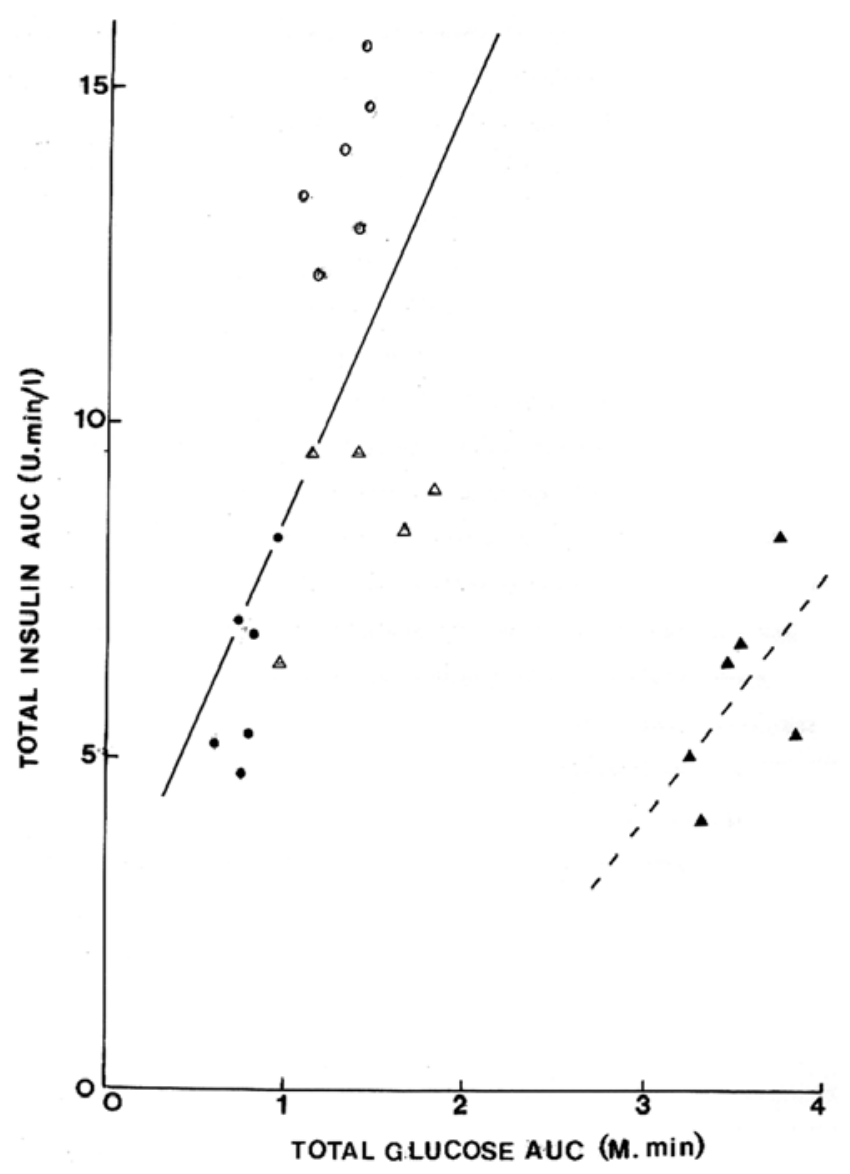

Figure 4. Relationship between the total insulin and D-glucose AUC during the IPGTT. Same presentation as in Fig. 2.

$\mathrm{n}=12$ ). This coincided, as illustrated in Fig. 1, with a more sustained secretory response of insulin-producing cells in the latter animals than in the former ones. Likewise, the relative magnitude of such a peak increment was higher $(\mathrm{p}<0.001)$ in the (Ssun) and (Fsun) rats $(160.8 \pm 19.2 \% ; n=12)$ than in the (Fsal) and (Fsaf) rats $(48.6 \pm 10.3 \%$; $n=11)$.

Both the total and incremental AUC for plasma insulin during the IPGTT were significantly higher $(\mathrm{p}<0.003$ or less) in the (Fsun) rats than in any of the other three groups of rats. The total AUC was also higher $(\mathrm{p}<0.02)$ in the (Fsal) rats than in either the (Ssun) or (Fsaf) rats. Thus, in this respect, the administration of the $\omega 3$-enriched diet, minimized, but did not abolish, the hyperinsulinemia otherwise caused by the substitution of starch by D-fructose, whilst the exposure to the $\omega 6$-enriched diet apparently exerted in the fructose-fed rats an unexpected and severe decrease in the secretory activity of insulin-producing cells, as already suggested by the data illustrated in Fig. 2.

The comparison between the total AUC for plasma insulin and D-glucose concentration (Fig. 4) yielded a pattern reminiscent of, albeit not identical to, that found between the basal values for plasma insulin and D-glucose concentrations (Fig. 2). Thus, the slope of the regression line for the data collected in the (Fsaf) rats (3.61) was no more significantly lower $(\mathrm{F}=0.231$, $\mathrm{f}=1,19 ; \mathrm{p}>0.25)$ than that recorded in the other rats (6.29), whilst the elevations of such regression lines differed vastly from one another $(\mathrm{F}=15.63, \mathrm{f}=1,20 ; \mathrm{p}<0.005)$. The paired ratio between the total insulin AUC/total D-glucose AUC yielded mean values displaying a hierarchy grossly comparable to that found for the insulinogenic index at time zero of the IPGTT, with, however, a higher mean value $(\mathrm{p}<0.004)$ in the (Fsun) rats $(10.83 \pm 0.45 \mathrm{U} / \mathrm{mol} ; \mathrm{n}=6)$ than in the (Ssun) rats $(81.0 \pm 0.53$ $\mathrm{U} / \mathrm{mol} ; \mathrm{n}=6)$, an even somewhat lower value $(\mathrm{p}<0.08)$ in the (Fsal) rats $(6.41 \pm 0.64 \mathrm{U} / \mathrm{mol} ; \mathrm{n}=5)$ and an extremely low value $(\mathrm{p}<0.001)$ in the (Fsaf) rats $(1.70 \pm 0.16 \mathrm{U} / \mathrm{mol} ; \mathrm{n}=6)$.

\section{Discussion}

The present study affords three major pieces of information: First, it documents that, even in sunflower oil fed-rats, the substitution of starch by D-fructose further impairs the tolerance to D-glucose. Thus, the plasma D-glucose concentration at time zero of the IPGTT, as well as both the total and incremental AUC for such a concentration during the IPGTT, were higher in the (Fsun) rats than in the (Ssun) rats. Such an impairment appeared mainly attributable to the deterioration of insulin sensitivity, as indicated by the increase in the HOMA index. The secretory responsiveness of pancreatic insulinproducing cells to D-glucose, however, was not adversely affected in the (Fsun) rats. Thus, no significant difference between (Ssun) rats and (Fsun) rats was observed in terms of the insulinogenic index at time zero of the IPGTT. The paired ratio between the total insulin AUC/total D-glucose AUC was even somewhat higher in the latter rats than in the former ones. 
Table IV. Plasma insulin concentration during the IPGTT.

\begin{tabular}{|c|c|c|c|c|c|}
\hline \multirow[t]{2}{*}{ Rats } & \multicolumn{2}{|c|}{ Peak increment } & \multicolumn{2}{|c|}{ AUC (U.min/l) } & \multirow[b]{2}{*}{ (n) } \\
\hline & Time (min) & $\Delta(\% \text { of basal })^{\mathrm{a}}$ & Total & Incremental $^{\mathrm{b}}$ & \\
\hline Ssun & $30.0 \pm 6.7$ & $128.2 \pm 19.0$ & $6.23 \pm 0.56$ & $0.74 \pm 0.46$ & (6) \\
\hline Fsun & $40.0 \pm 9.2$ & $193.4 \pm 28.9$ & $13.88 \pm 0.59$ & $5.89 \pm 0.92$ & (6) \\
\hline Fsal & $18.0 \pm 3.0$ & $53.2 \pm 13.3$ & $8.56 \pm 0.57$ & $0.58 \pm 0.81$ & (5) \\
\hline Fsaf & $17.5 \pm 2.5$ & $44.8 \pm 16.3$ & $6.00 \pm 0.63$ & $0.45 \pm 0.48$ & (6) \\
\hline
\end{tabular}

${ }^{a}$ The peak increment refers to the difference above the mean of the zero time measurement and later nadir value (reached at min $98 \pm 6 ; n=23) .{ }^{b}$ The increment AUC corresponds to the total AUC minus the value derived from the time zero and min 120 measurements.

Such a difference may well reflect a functional adaptation of insulin-producing cells to the fructose-induced deterioration of insulin sensitivity.

Second, despite a trend towards a decrease in the HOMA index (Fig. 3) the enrichment of the fructose-containing diet by long-chain polyunsaturated $\omega 3$ fatty acids failed to affect significantly the plasma D-glucose concentration at time zero of the IPGTT, as well as either the total or incremental AUC for such a concentration during the IPGTT, when comparing the (Fsal) rats to the (Fsun) rats. This coincided with the fact that, in the former (Fsal) rats, the peak increment in plasma insulin concentration during the IPGTT occurred earlier and displayed a lower relative value than in the (Fsun) rats. Moreover, both the total and incremental AUC for plasma insulin concentration during the IPGTT were also lower in the (Fsal) rats than in the (Fsun) rats. Likewise, the paired ratio between the total insulin AUC/total D-glucose AUC during the IPGTT yielded a lower mean value in the (Fsal) rats than in the (Fsun) rats. Taken as a whole, these results suggest that, in the (Fsal) rats, a modest improvement of insulin sensitivity was opposed, in terms of glucose homeostasis, by a decreased secretory response of insulin-producing cells to a rise in plasma D-glucose concentration. The latter situation is reminiscent of that recorded in isolated pancreatic islets, when comparing the insulinotropic action of several secretagogues in islets from 2nd generation $\omega 3$-depleted rats to that of control animals both exposed to diets not enriched with D-fructose, the output of insulin being higher in the $\omega 3$-depleted rats than in the control animals $(11,12)$.

Last, the present results reveal a severe deterioration of glucose homeostasis when comparing (Fsaf) rats to (Fsun) rats. The plasma D-glucose concentration at time zero of the IPGTT, the peak increment in such a concentration during the IPGTT, and both the total and incremental AUC for plasma D-glucose concentration during the IPGTT were indeed all much higher in the (Fsaf) rats than in the (Fsun) rats. In the (Fsaf) rats, such a deterioration of glucose homeostasis coincided with and was probably attributable to both the highest mean values for the HOMA index (Fig. 3) and a severe decrease in the insulin-producing cell responsiveness to D-glucose as judged from the insulinogenic index at time zero of the IPGTT (Table II), the lowest mean values for both the total and incremental AUC for plasma insulin concentra- tion during the IPGTT (Table IV) and the extremely low paired ratio between the total insulin AUC/total D-glucose AUC during the same IPGTT (Fig. 4).

These findings call for further investigations, as documented by the following examples. First, the time course for the changes of metabolic and hormonal variables during exposure to the different diets merits consideration. Second, experiments in isolated islets seem desirable in order to identify possible changes in islet insulin content, as well as a possible alteration of their metabolic and secretory response to D-glucose and other nutrient secretagogues. Third, and in a non-exhaustive manner, attention should be given to other factors such as the plasma concentration of non-carbohydrate nutrients and selected lipids, susceptible to interfere in vivo with insulin secretion and/or insulin sensitivity.

\section{Acknowledgments}

We are grateful to C. Demesmaeker for secretarial help.

\section{References}

1. Boukortt FO, Madani Z, Mellouk Z, Louchami K, Sener A and Ait Yahia D: Nutritional factors and fructose-induced metabolic syndrome. Metab Funct Res Diab (In press).

2. Cancelas J, Prieto PG, Garcia-Arevalo M, Sancho V, VillanuevaPeñacarrillo ML, Malaisse WJ and Valverde I: Induction and reversibility of insulin resistance in rats exposed to exogenous D-fructose. Horm Metab Res 40: 459-466, 2008.

3. Carpentier YA, Peltier S, Portois L, Sebedio JL, Leverve X and Malaisse WJ: Rapid reduction of liver steatosis in $\omega 3$-depleted rats injected with a novel lipid emulsion. Horm Metab Res 40: 875-879, 2008

4. Oguzhan B, Sancho V, Acitores A, Villanueva-Peñacarrillo ML, Portois L, Chargidny J-M, Sener A, Carpentier YA and Malaisse WJ: Alteration of adipocyte metabolism in $\omega 3$ fatty acid-depelted rats. Horm Metab Res 38: 789-798, 2006.

5. Sener A, Zhang Y, Bulur N, Louchami K, Malaisse WJ and Carpentier YA: The metabolic syndrome of $\omega 3$-depleted rats. II. Body weight, adipose tissue mass and glycemic homeostasis. Int J Mol Med 24: 125-129, 2009.

6. Cancelas J, Prieto AG, Villanueva-Peñacarrillo ML, Zhang Y, Portois L, Sener A, Carpentier YA, Valverde I and Malaisse WJ: Glucose intolerance associated to insulin resistance and increased insulin secretion in rats depleted in long-chain polyunsaturated $\omega 3$ fatty acids. Horm Metab Res 39: 823-825, 2007.

7. Peltier S, Malaisse WJ, Portois L, Demaison L, Novel-Chate V, Chardigny J-M, Sebedio JL, Carpentier YA and Leverve XM: Acute in vivo administration of a fish oil-containing emulsion improves post-ischemic cardiac function in $n-3$ depleted rats. Int J Mol Med 18: 741-749, 2006. 
8. Armitage JA, Pearce AD, Sinclair AJ, Vingrys AJ, Weisinger RS and Weisinger HS: Increased blood pressure later in life may be associated with perinatal n-3 fatty acid deficiency. Lipids 38: 459-464, 2003.

9. Bergmeyer HU and Berndt E: Glucose determination with glucose oxidase and peroxidase. In: Methods of Enzymatic Analysis. Bergmeyer HY (ed). Academic Press, New York, pp1205-1215, 1974.

10. Leclercq-Meyer V, Marchand J, Woussen-Colle MC, Giroix M-H and Malaisse WJ: Multiple effects of leucine on glucagon, insulin and somatostatin secretion from the perfused rat pancreas. Endocrinology 116: 1168-1174, 1985.
11. Oguzhan B, Zhang Y, Louchami K, Courtois P, Portois L, Chardingy J-M, Malaisse WJ, Carpentier YA and Sener A: Pancreatic islet function in $\omega 3$ fatty acid-depleted rats. Glucose metabolism and nutrient-stimulated insulin release. Endocrine 29: 457-466, 2006.

12. Zhang Y, Oguzhan B, Louchami K, Chardigny J-M, Portois L, Carpentier YA, Malaisse WJ, Herchuelz A and Sener A: Pancreatic islet function in $\omega 3$ fatty acid-depleted rats: alteration of calcium fluxes and calcium-dependent insulin release. Am J Physiol 291: E441-E448, 2006. 